\title{
The relationship of bicycle manoeuvrability to handlebar configuration
}

\author{
R.G. Mortimer ${ }^{1}$, Patricia A. Domas ${ }^{2}$ and R.E. Dewar ${ }^{3}$ \\ ${ }^{1}$ Head, Human Factors Department, Highway Safety Research Institute, University of Michigan, now \\ at Department of Health and Safety Education, University of Illinois, USA. \\ ${ }^{2}$ Research Assistant, Human Factors Department, HSRI \\ ${ }^{3}$ Associate Professor, Department of Psychology, University of Calgary, Visiting Scientist at HSRI
}

Since the handling characteristics of bicycles can affect their safety, the present experiment evaluated the manoevrability of three bicycles which differed only by handlebar configurations: racing (Maes Bend), standard, and high rise. The manoeuvrability of each bicycle was measured as subjects performed six tasks: circle, lane change, figure-eight, straight lane tracking, cornering, and slalom. Subjects were matched by riding experience and grouped by their familiarity with either race or standard bicycle. Analysis of variance showed that no bicycle times bicycle-familiarity interaction effects were significant in any one of the analyses.

The performances observed on the bicycles with high-rise and standard handlebar configurations indicated they were not significantly different from each other. On the circle, figure-eight, and slalom tasks, performance with both the high-rise and standard handlebars was significantly better than with the race handlebars. The high-rise showed a slight performance edge on tasks requiring the greatest amount of manoeuvrability, while the standard handlebars offered more control at slower speeds and on tasks requiring stability in tracking.

\section{Introduction}

The popularity of cycling has grown considerably each year for the past decade in the USA, with 80 million bicycles in use in 1973. This increased use of bicycles by all age groups can be expected to affect the impact of bicycles as a highway safety problem. The US Department of Health, Education and Welfare (1972) estimated that 1000000 injuries involved bicycle riders in 1969, of which 39000 were related to collisions with motor vehicles (National Safety Council, 1970). In 1973 there were 1150 deaths as a result of motor-bicycle collisions (National Safety Council, 1974), compared with 460 in 1960 . As the use of the bicycle has increased, bicycle-related deaths and injuries have grown in number consistently through the years.

In a special study of bicycle safety, the National Transportation Safety Board (1972) recognized that specific design features have accident-injury potential. A tradeoff exists between manoeuvrability and stability, where greater manoeuvrability leads to decreased stability and possibly to more dangerous rider behaviour. The introduction of the 'high-rise' bicycle configuration (characterized by high handlebars, banana seat, smaller wheels, shorter wheelbase) has attracted attention to bicycle design features and their inherent safety aspects. The NTSB states that, al though the issue has been insufficiently studied, there is reason to believe that the newer high-rise bicycle may be a more hazardous overall design than the conventional style. This attitude, coupled with an increasing number of bicyclerelated accidents, has prompted investigations of the characteristics of all bicycle types.

In an attempt to relate the occurrence of accidents to specific characteristics of bicycle usage, Campbell, Foley and Pascarella (1971) studied bicycle accidents among youths in Raleigh, NC. Unique to this experiment was the use of 'cyclometers' to measure the exposure of riders in terms of actual miles ridden. A survey of bicycle riding and accidents was maintained on a sample of 500 youths and supplemented by city-wide hospital and police reports. The experimental design allowed estimation of accident rates by bicycle type and rider sex and age, corrected for exposure in terms of mileage. The data indicated that rider involvement in a minor accident would occur on an average of once in two years, and a serious accident requiring medical attention once in 25 years. The contention that any particular bicycle type, including high-rise, is associated with a higher accident rate, was not supported, nor was type of bicycle significantly associated with injury severity or body area injured.

A study of bicycle accidents among children in Metropolitan Toronto (Ontario Department of Transport, 
1970 ) indicated that out of 275 accidents, $51 \%$ involved bicycles with standard handlebars and seat, whereas $37 \%$ involved high-rise handlebars and banana seat, while the remainder were some different combination of handlebars and seat styles. High-rise handlebars seem to have been under-represented in these accident data, in view of the findings that they constituted $53 \%$, whereas the standard configuration represented only $35 \%$ of a control group of 761 bicycles owned by children of comparable age.

A study conducted at the Cornell Aeronautical Laboratory by Rice and Roland (1970) considered bicycles from a human engineering point-of-view and identified several factors involved in the manoeuvrability of some common bicycle designs. This study evaluated the performance and handling qualities of conventional and high-rise bicycles. Approaching the question experimentally, the authors obtained quantitative measurements of handling characteristics as several riders performed a series of manoeuvres: braking, steady-state cornering, hands-off path following, and serpentine tracking. In the tests which were performed, the conventional bicycle was just as manoeuvrable at moderate speeds $(16-24 \mathrm{~km} / \mathrm{h} ; 10-15 \mathrm{mile} / \mathrm{h})$ as the highrise bicycle. Although they did not conclude that all manoeuvres could be performed equally well with either bicycle, they did suggest that the high-rise bicycle outperforms the conventional design only in acrobatics and in situations where its shorter overall length is essential to success. As a first step towards the development of performance standards and consumer information, the authors recommended further experimental work and accident causation studies linking design characteristics and safety.

In the experiment presented here, the question of the performance characteristics of a specific feature of bicycle designs was examined. A sample of riders and a variety of riding tests were used to evaluate the maneouvrability of bicycles having three basic handlebar configurations - racing (Maes Bend), standard, and high-rise (see Fig. 1). The tests used in this evaluation included variations of those used by Rice and Roland ( $o p$ cit), and additional tests involving manoeuvring that might be required in an emergency. None of the tests involved braking.

The purpose of the experiment was to compare the handlebar configurations, which will simultaneously affect (a) the rider's position, (b) the centre of gravity of the riderbicycle combination and (c) the lateral spacing between the rider's hands on the grips of the handlebars, which were narrowest on the race and widest on the high-rise. No other bicycle design characteristics were varied. The present study differed from that of Rice and Roland (op cit) in that they compared different bicycle models while we compared handlebar configurations only.

\section{Method \\ Design}

A within-subject design was employed, with each subject riding all three bicycles. The manoeuvrability of each bicycle was measured as the subject performed six different tasks (circle, lane change, figure-eight, straight lane tracking, cornering, and slalom). The order in which bicycles were ridden was predetermined and counterbalanced across subjects.

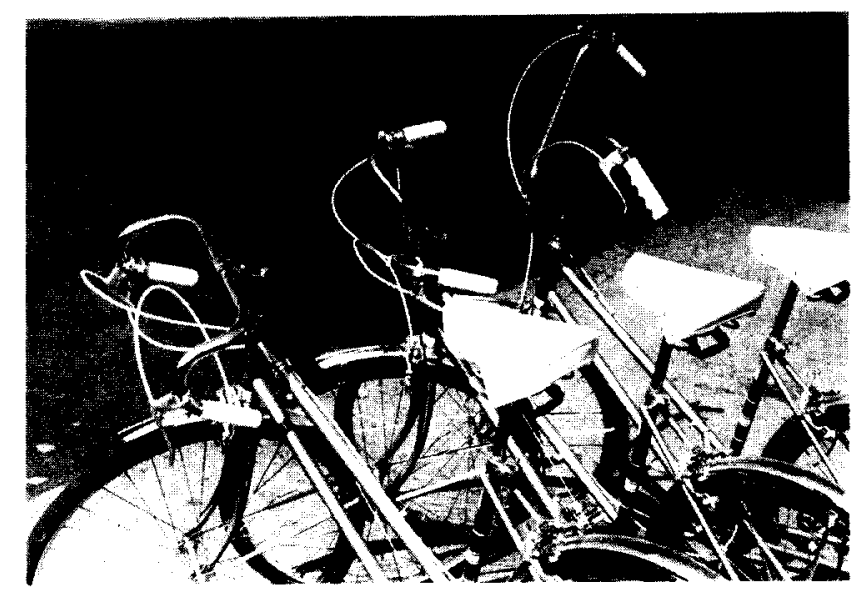

Fig. 1 The handlebar configurations: racing, standard, high-rise

Attempts were made to control practice effects resulting from both the tasks and the bicycles. Tasks of a similar nature, for example, circle and figure-eight, lane change and straight lane tracking, were separated in the sequence by one other task. The subjects performed the tasks in one of two orders: circle first, and then as ordered above in the preceding paragraph, or in the reverse order with the slalom task first. These two blocks of tasks were then presented in one of two ways. First, the subject performed all the tasks in the given order on the same bicycle, then proceeded to the second and third bicycles and repeated the tasks in the same order. Or, second, the subject completed one task at a time, using all three bicycles in the predetermined order; and then proceeded to the next task. Both the order of tasks and the presentation order of the block of tasks were counterbalanced across subjects.

\section{Subjects}

Eighteen men served as paid subjects. They were employees of the Highway Safety Research Institute or students at the University of Michigan. Their ages ranged from 18 to 41 , with an average of 24 years.

Subjects were screened for their bicycle riding experience. Two extremes were avoided: those men who rode every day or more than $8 \mathrm{~km}$ ( 5 miles) per week, and those who had not ridden bicycles for several months. On the average, subjects rode once or twice a week. Seven subjects were most familiar with racing handlebars, and two were familiar with two or more bicycle types. The remaining nine predominantly rode bicycles with standard handlebar configurations.

\section{Apparatus}

With the exception of the handlebars, the bicycles were the identical women's model with $508 \mathrm{~mm}$ (20 in) frames (ie, length from top of seat post to crankshaft). Taking the longitudinal and lateral mid points of the hand grips as references, the distances between these points were measured to indicate the width of the handlebars. These distances were: high-rise, $584 \mathrm{~mm}$ (23 in); standard, $482 \mathrm{~mm}$ (19 in); race, $381 \mathrm{~mm}$ (15 in).

The bicycles were equipped with 3 -speed gear shifts and front and rear brakes. During the experiment, however, the subjects were restricted to the use of second gear only. In addition to the experimental bicycles, a fourth bicycle was 
used for pacing on all trials in which the subject was required to maintain a specific speed. It was equipped with a speedometer, which was accurately calibrated for use in the experiment.

Supplementary equipment included traffic cones, a stop watch and an additional timing device, consisting of a step switch and ten counters which allowed multiple times to be recorded consecutively in the lane-change task.

\section{Procedure}

For each subject the height of the bicycle's seat was adjusted so that the rider's feet were about fully extended when the pedals were in their lowest position. The handlebar stem was set at the same height as the seat.

Each subject was assigned to one of six bicycle orders, one of the two task orders within a block, and one of the two presentation orders of the block of tasks. Each bicycle was used on all six tasks.

The instructions for each task, and the measures taken on each, were as follows:

\section{Circle}

The subject was instructed to pedal around the circle within its boundaries as fast as possible. The lane was $1.22 \mathrm{~m}$ $(4 \mathrm{ft})$ wide, with inner and outer radii of 2.74 and $3.96 \mathrm{~m}$ ( 9 and $13 \mathrm{ft}$ ) respectively. The direction of travel, clockwise or counterclockwise, was at the subject's option. However, once the subject chose the direction, he was limited to it for all three bicycles. An error was recorded each time the front wheel of the bicycle crossed over the outer or inner boundaries. The subject was instructed to sacrifice accuracy for speed, up to the point that errors cost him additional time.

The subject practised three times around the circle and then rested. One experimental trial consisted of a complete revolution around the circle. Before the experimental trials began, the subject was given one to two revolutions to attain speed. Time was measured on five consecutive trials.

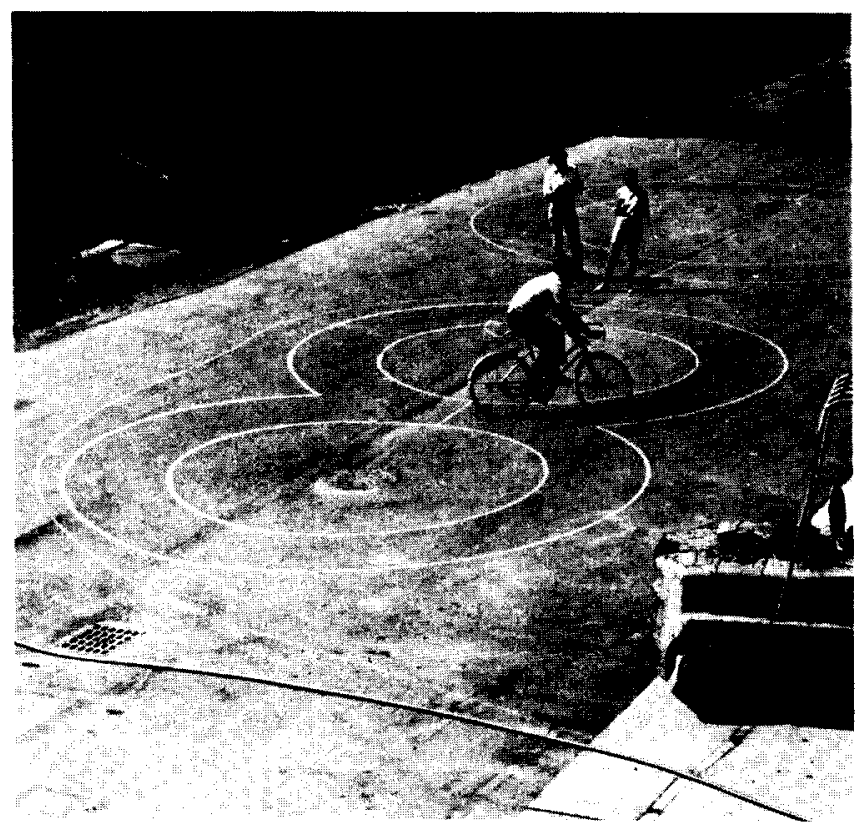

Fig. 2 The figure-eight task

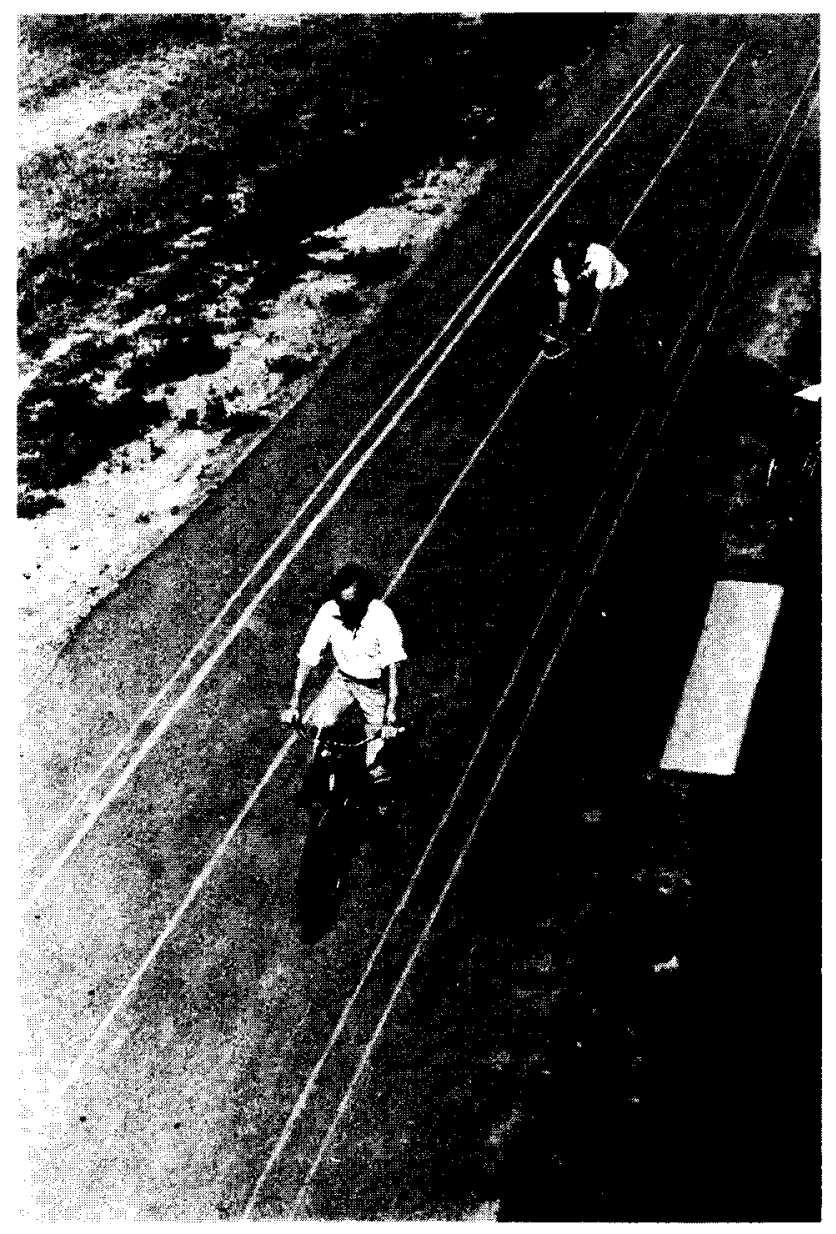

Fig. 3 The lane change task, with the pace bicycle in the foreground and the subject beginning to cross from the left to the right lane

\section{Figure-eight}

The lane on each loop of the figure-eight was $914 \mathrm{~mm}$ $(3 \mathrm{ft}$ ) wide, with an inner radius of $1.83 \mathrm{~m}(6 \mathrm{ft}$ ) (Fig. 2). The instructions and procedure for the figure-eight were similar to those for the circle. However, the direction of travel was specificed for all subjects. Time was recorded for four consecutive trials.

\section{Lane change}

This task required the subject to steer his bicycle in a lane $203 \mathrm{~mm}$ ( 8 in) wide (Fig. 3 ) as he was paced at $19 \cdot 31 \mathrm{~km} / \mathrm{h}(12 \mathrm{mile} / \mathrm{h})$. On a given signal the subject crossed over to the second lane $1.83 \mathrm{~m}(6 \mathrm{ft})$ away as quickly as possible. After crossing, the subject was to steer in the second lane and remain in it until the end. One experimental trial consisted of one lane change with only one crossover signal given during the $30.48 \mathrm{~m}(100 \mathrm{ft})$ run.

The subject practised one lane change, travelling right to left. Measures of time were recorded on four trials, two changes right to left, and two changes left to right. The measures taken were initiation time, crossover time, and stabilization time. Initiation time began with the experimenter's signal and ended when the subject reacted by leaving the first lane. Crossover time began at this point and ended when the front wheel of the bicycle crossed the inner boundary of the second lane. Stabilization time began at this point and was measured until the subject began to stay within the second lane to its end. If he crossed into 
the second lane and never left it, or remained in it for at least $1 \mathrm{~s}$, stabilization time was recorded as zero.

\section{Straight lane tracking}

The straight lane tracking task required the subject to steer his bicycle in a lane $203 \mathrm{~mm}$ ( 8 in) wide and $24.99 \mathrm{~m}$ $(82 \mathrm{ft})$ long. An error was recorded whenever the front tyre of the bicycle crossed outside either of the lane boundaries. Measures of error frequency were taken on two trials at both $4.83 \mathrm{~km} / \mathrm{h}(3 \mathrm{mile} / \mathrm{h})$ and $19.31 \mathrm{~km} / \mathrm{h}(12 \mathrm{mile} / \mathrm{h})$. The subject practised one trial at each speed before beginning the experimental trials with each bicycle

\section{Cornering}

Subjects were paced through a $914 \mathrm{~mm}(3 \mathrm{ft})$ lane at $16.09 \mathrm{~km} / \mathrm{h}(10 \mathrm{mile} / \mathrm{h})$, and instructed to make a sharp right turn after passing a pair of traffic cones (Fig. 4). The criterion emphasized was turning with as small a radius as possible. The subject was not allowed to use brakes or his feet in the turn, but was told to coast around the corner. The turning radii were marked on the pavement from $610 \mathrm{~mm}$ to $4.88 \mathrm{~m}(2-16 \mathrm{ft})$ in $152 \mathrm{~mm}(6$ in) intervals. The performance measure recorded was the furthest line crossed as the subjects made the turn. These distances were recorded for six turning trials, all of which were used in the analyses of the data.

\section{Slalom}

The slalom task involved a zig-zag course through nine traffic cones spaced $3.05 \mathrm{~m}(10 \mathrm{ft})$ apart in a lane $1.07 \mathrm{~m}$ $(3.5 \mathrm{ft}$ ) wide (Fig. 5). The bases of the cones were cut off, making them easy to tip over. The performance criterion that was emphasized to the subjects was to ride through the course without knocking over any of the cones. Whenever the front wheel of the bicycle crossed over the lane boundaries, an error was recorded.

The subject was paced through the course at four speeds $8 \cdot 05,12 \cdot 87,16.09$ and $19 \cdot 31 \mathrm{~km} / \mathrm{h}(5,8,10$, and $12 \mathrm{mile} / \mathrm{h})$

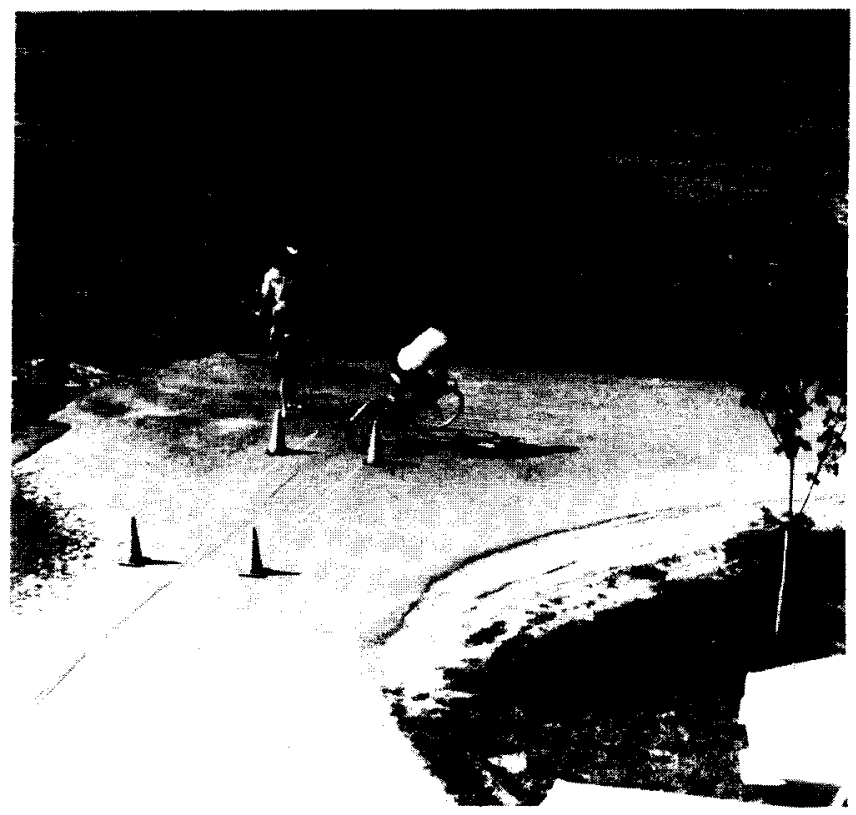

Fig. 4 The cornering task

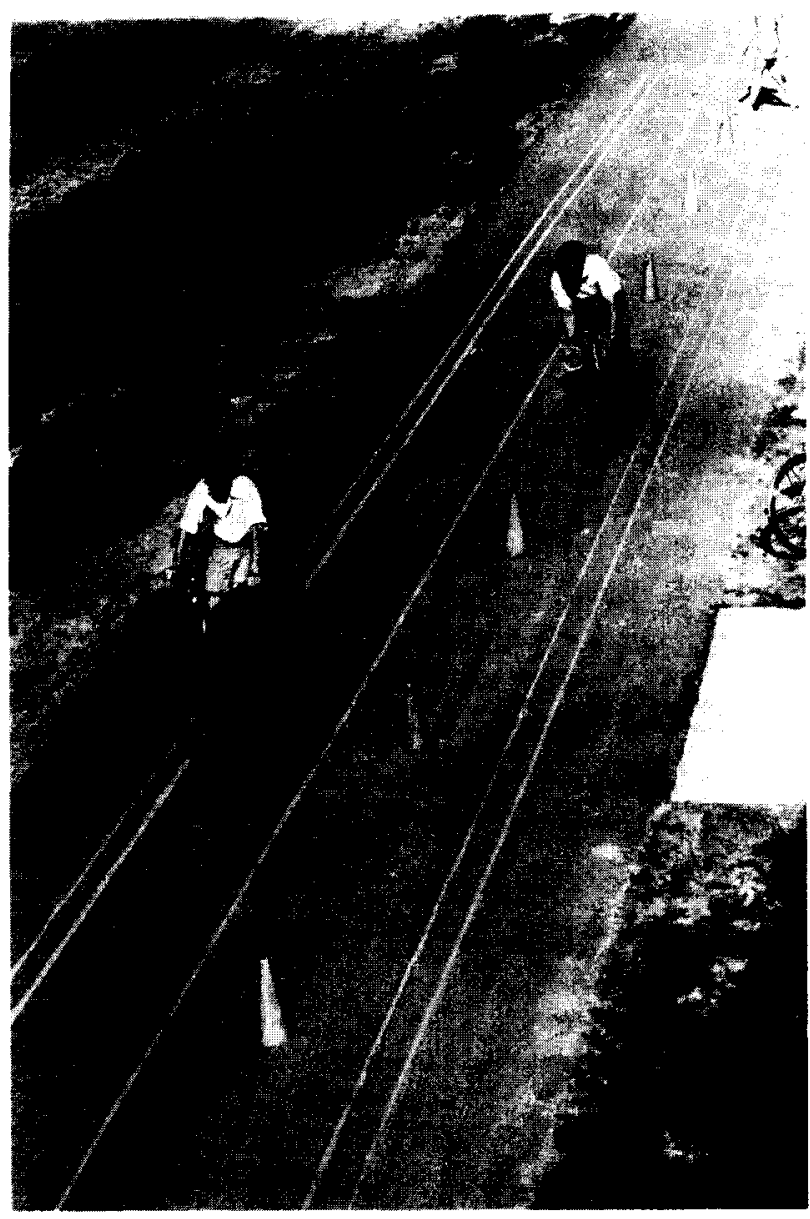

Fig. 5 The slalom task

in that order. The subject was allowed to ride slower than the pacing bicycle if necessary, but never faster. The subject was allowed one practise trial at $8.05 \mathrm{~km} / \mathrm{h}(5 \mathrm{mile} / \mathrm{h})$, and then had two trials at the next higher speed. If he failed on both trials at a speed he did not try again at any other speed on that bicycle. The performance measure recorded was the maximum speed through the course without knocking over any cones.

\section{Ratings of manoeuvrability and task difficulty}

In addition to recording the performance measures described, subjects were asked to rate each bicycle for its manoeuvrability on each task, as soon as the task was completed. A five-point scale was used with the following assignments: $1=$ very easy, $2=$ easy, $3=$ neutral, $4=$ hard, and $5=$ very hard. Using the same scale, subjects were also asked to rate the overall difficulty of each task independently of the bicycles they had ridden, when it had been completed with all bicycles.

\section{Results}

Ten performance measures were subjected to the analysis of variance (ANOVA): circle time; figure-eight time; lane change initiation time, crossover time, stabilization time, and total time; straight lane tracking error at 4.83 and $19.31 \mathrm{~km} / \mathrm{h}$ ( 3 and $12 \mathrm{mile} / \mathrm{h}$ ); cornering distance; and slalom maximum successful speed. The Newman-Keuls test was used to make post-hoc comparisions among the treatment means. 


\section{Bicycle familiarity effects}

A subset of 23 subjects was divided into two groups in order to test bicycle times familiarity interactions. These subjects were matched on riding experience and grouped by their familiarity with either the race or standard handlebars. An ANOVA was performed on each of the 10 performance measures outlined above.

No bicycle times familiarity effects were significant in any of the analyses. Main effects due to the familiarity groups are outlined in Table 1 for each of the 10 performance measures. Significant differences between the two familiarity groups were found in only two tasks: circle time and cornering distance. That is, on these two tasks, subjects who were familiar with the race handlebars performed significantly better on both the race and standard bicycles than did those who were familiar with the standard bicycle. While the significantly better performance of the group familiar with the race bicycle on two tasks suggests the group's overall superiority, the differences between the familiarity groups are obviously small.

Since no bicycle times familiarity interactions were found, the remainder of the analyses presented here concern the entire sample of 18 subjects.

\section{Performance differences among types of handlebars}

Means and standard deviations of the 10 performance measures are shown in Table 2. The ANOVA's performed indicated significant differences in mean performance
Table 1: Mean performance by familiarity with bicycle configuration ( 6 subjects per group)

\begin{tabular}{|c|c|c|c|}
\hline \multirow[t]{2}{*}{ Performance measure } & \multicolumn{2}{|c|}{ Bicycle familiarity group } & \multirow[t]{2}{*}{$\mathbf{P}$} \\
\hline & Standard & Race & \\
\hline Circle time (s) & 5.34 & 4.89 & $<0.01$ \\
\hline Figure-eight time $(s)$ & 8.54 & 8.24 & NS \\
\hline $\begin{array}{l}\text { Lane change, initiation } \\
\text { time (s) }\end{array}$ & $0 \cdot 71$ & 0.66 & NS \\
\hline $\begin{array}{l}\text { Lane change, crossover } \\
\text { time (s) }\end{array}$ & $1 \cdot 37$ & $1 \cdot 37$ & NS \\
\hline $\begin{array}{l}\text { Lane change, stabilization } \\
\text { time }(s)\end{array}$ & $0 \cdot 19$ & $0 \cdot 40$ & NS \\
\hline Lane change, total time (s) & $2 \cdot 27$ & $2 \cdot 43$ & NS \\
\hline $\begin{array}{r}\text { Cornering distance }- \text { metres } \\
\text { (feet) }\end{array}$ & $\begin{array}{c}3.60 \\
(11.81)\end{array}$ & $\begin{array}{c}2 \cdot 93 \\
(9 \cdot 61)\end{array}$ & $<0.05$ \\
\hline $\begin{array}{l}\text { Straight lane tracking } \\
\text { error }-4.83 \mathrm{~km} / \mathrm{h} \text { ( } 3 \text { mile } / \mathrm{h} \\
\text { (frequency) }\end{array}$ & h) 1.42 & $2 \cdot 19$ & NS \\
\hline $\begin{array}{l}\text { Straight lane tracking } \\
\text { error }-19.31 \mathrm{~km} / \mathrm{h} \text { (12 mile } \\
\text { frequency }\end{array}$ & e/h) 0.55 & 0.44 & NS \\
\hline $\begin{array}{l}\text { Slalom maximum speed }-\mathrm{m} \\
\qquad \mathrm{ft} / \mathrm{s}\end{array}$ & $\begin{array}{l}n / s \quad 4.41 \\
\text { (s) }(14.47)\end{array}$ & $\begin{array}{c}4.29 \\
(14 \cdot 06)\end{array}$ & NS \\
\hline
\end{tabular}

NS = Not significant

Table 2: Means and standard deviations for 18 subjects of riding performance for different bicycle configurations

\begin{tabular}{|c|c|c|c|c|c|c|}
\hline \multirow{3}{*}{ Performance measure } & \multicolumn{6}{|c|}{ Type of handlebar } \\
\hline & \multicolumn{2}{|c|}{ High-rise } & \multicolumn{2}{|c|}{ Standard } & \multicolumn{2}{|c|}{ Race } \\
\hline & Mean & SD & Mean & SD & Mean & SD \\
\hline Circle time (s) & $\underline{5 \cdot 116}^{*}$ & 0.365 & $\underline{5 \cdot 108}$ & 0.410 & $5 \cdot 264$ & 0.452 \\
\hline Figure-eight time $(\mathrm{s})$ & $8 \cdot 255$ & 0.645 & $8 \cdot 366$ & 0.732 & $8 \cdot 701$ & 0.673 \\
\hline $\begin{array}{l}\text { Lane change initiation } \\
\text { time }(s)\end{array}$ & 0.631 & $0 \cdot 138$ & 0.649 & 0.171 & 0.652 & $0 \cdot 142$ \\
\hline $\begin{array}{l}\text { Lane change crossover } \\
\text { time (s) }\end{array}$ & $1 \cdot 408$ & 0.244 & $1 \cdot 331$ & $0 \cdot 261$ & 1.424 & $0 \cdot 294$ \\
\hline $\begin{array}{l}\text { Lane change stabilization } \\
\text { time (s) }\end{array}$ & 0.448 & 0.523 & 0.372 & 0.349 & 0.506 & 0.386 \\
\hline Lane change total time (s) & $2 \cdot 493$ & 0.218 & $2 \cdot 350$ & $0 \cdot 108$ & $2 \cdot 584$ & 0.181 \\
\hline $\begin{array}{r}\text { Cornering distance }- \text { metre } \\
(\mathrm{ft})\end{array}$ & $\begin{array}{c}3 \cdot 18 \\
(10 \cdot 425)\end{array}$ & $\begin{array}{l}0.68 \\
(2 \cdot 225)\end{array}$ & $\begin{array}{c}3 \cdot 21 \\
(10 \cdot 541)\end{array}$ & $\begin{array}{l}0.67 \\
(2 \cdot 196)\end{array}$ & $\begin{array}{c}3 \cdot 35 \\
(10 \cdot 981)\end{array}$ & $\begin{array}{l}0 \cdot 70 \\
(2 \cdot 291)\end{array}$ \\
\hline $\begin{array}{l}\text { Straight lane tracking at } \\
4.83 \mathrm{~km} / \mathrm{h}(3 \mathrm{mile} / \mathrm{h}) \\
\text { (error frequency) }\end{array}$ & $2 \cdot 083$ & $2 \cdot 033$ & $1 \cdot 805$ & $1 \cdot 653$ & $2 \cdot 000$ & $1 \cdot 788$ \\
\hline $\begin{array}{l}\text { Straight lane tracking at } \\
19 \cdot 31 \mathrm{~km} / \mathrm{h}(12 \mathrm{mile} / \mathrm{h}) \\
\text { (error frequency) }\end{array}$ & 0.388 & 0.728 & 0.472 & 0.608 & 0.583 & 0.806 \\
\hline $\begin{array}{l}\text { Slalom maximum } \\
\text { successful speed }-\mathrm{m} / \mathrm{s} \\
\qquad(\mathrm{ft} / \mathrm{s})\end{array}$ & $\begin{array}{c}4.56 \\
(14.973) \\
\end{array}$ & $\begin{array}{l}0.55 \\
(1.817)\end{array}$ & $\begin{array}{c}4 \cdot 38 \\
(14 \cdot 354) \\
\end{array}$ & $\begin{array}{l}0.77 \\
(2.516)\end{array}$ & $\begin{array}{c}3 \cdot 82 \\
(12 \cdot 519)\end{array}$ & $\begin{array}{l}0.96 \\
(3 \cdot 133)\end{array}$ \\
\hline
\end{tabular}

A mean which is underlined in a given row is significantly better $(\rho<0.01)$ than any mean which is not underlined in the same row. Where two means are underlined in a given row, there is no significant difference between them. Where no means are underlined in a given row, there is no significant difference between any of them. 
among bicycles on three measures: circle time, figure-eight time; and slalom maximum successful speed.

The analysis of circle times indicated that both the standard and high rise bicycles were significantly faster than the race $(\rho<0.01)$, but not different from each other. The average lateral acceleration on each bicycle, high-rise, standard, and race, was calculated to be $5 \cdot 10 \mathrm{~m} / \mathrm{s}^{2}(0.52 \mathrm{~g})$, $5 \cdot 10 \mathrm{~m} / \mathrm{s}^{2}(0.52 \mathrm{~g})$, and $4.81 \mathrm{~m} / \mathrm{s}^{2}(0.49 \mathrm{~g})$, respectively. This limit was probably affected by pedal clearance while banking the bicycle.

On the figure-eight, both standard and high-rise bicycles were faster than the race $(\rho<0.01)$, but, again not significantly different from each other.

On all three bicycles in the straight lane task, subjects made significantly more errors at $4.83 \mathrm{~km} / \mathrm{h}(3 \mathrm{mile} / \mathrm{h})$ than at $19 \cdot 31 \mathrm{~km} / \mathrm{h}(12 \mathrm{mile} / \mathrm{h})$. This emphasizes the decreased stability of the bicycles at low speeds. The error differences between bicycles were not significant at either speed. However, the trend in errors indicated that at the lower speed most errors were made on the high-rise, and at the higher speed most errors were made on the race bicycle. At $4.83 \mathrm{~km} / \mathrm{h}(3 \mathrm{mile} / \mathrm{h})$ the standard bicycle had the least errors. The results suggest that the conventional bicycle is more controllable at lower speeds.

The analysis of maximum successful speed on the slalom task indicated no significant differences between the standard and high-rise bicycles. However, in this task these bicycles allowed a significantly higher speed to be reached over the course than did the race bicycle.

Fig. 6 shows the mean performances on the race and highrise bicycles, relative to the standard bicycle on all tasks and performance measures. On all 10 measures the performance on the race bicycle was relatively poorer than on the standard and high-rise, and significantly poorer on three measures. Performance on the high-rise was relatively (but not significantly) poorer than the standard on the measures of circle time; lane change (total time, crossover time, and stabilization time), and straight lane tracking errors at $4.83 \mathrm{~km} / \mathrm{h}(3 \mathrm{mile} / \mathrm{h})$.

\section{Subjective ratings}

The ANOVA of the bicycle manoeuvrability ratings indicated a bicycle times test interaction. The high-rise was rated as the easiest bicycle to manoeuvre on the comering, figure-eight, and slalom tasks. On the circle, the straight lane tracking task at $4.83 \mathrm{~km} / \mathrm{h}(3 \mathrm{mile} / \mathrm{h})$, and lane change, the standard bicycle was rated as most manoeuvrable. The race bicycle was rated as easiest to handle on the straight lane tracking at $19.31 \mathrm{~km} / \mathrm{h}(12 \mathrm{mile} / \mathrm{h})$. Except for the lat ter rating, the bicycle that was rated easiest to manoeuvre also was the bicycle with the best performance, as shown in Table 3. Averaged over all the tests, the high-rise and standard bicycles were rated equally manoeuvrable (mean rating 2.6 ) with the race evaluated as slightly more difficult to manoeuvre (mean rating 2.8 ). The overall ratings of difficulty of each task are shown in Table 4, indicating that riding at $4.83 \mathrm{~km} / \mathrm{h}(3 \mathrm{mile} / \mathrm{h})$ was considered most difficult.

\section{Discussion}

The performance observed on the bicycles with high-rise and standard handlebar configurations indicated they were

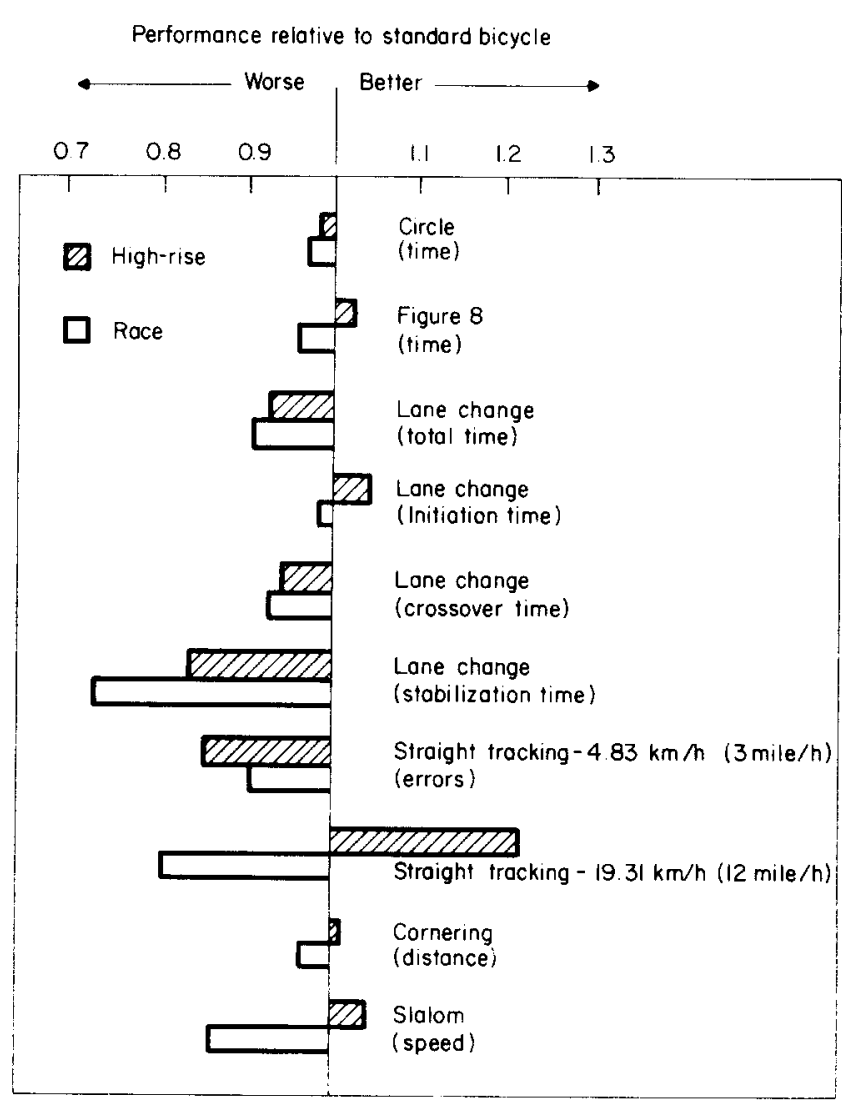

Fig. 6 Relative performance, using performance on the standard bicycle as a baseline, on high-rise and race bicycles on 10 measures

Table 3: Comparison, in terms of performance and rating, of the bicycle easiest to manoeuvre in each task

\begin{tabular}{lll}
\hline \multicolumn{1}{c}{ Task } & \multicolumn{1}{c}{$\begin{array}{c}\text { Mean } \\
\text { performance }\end{array}$} & $\begin{array}{l}\text { Mean } \\
\text { rating }\end{array}$ \\
\hline $\begin{array}{l}\text { Tracking at } 19 \cdot 31 \mathrm{~km} / \mathrm{h} \\
(12 \mathrm{mile} / \mathrm{h})\end{array}$ & High-rise & Race \\
Circle & Standard & Standard \\
Lane change & Standard & Standard \\
Cornering & High-rise & High-rise \\
Slalom & High-rise & High-rise \\
Figure-eight & High-rise & High-rise \\
Tracking at $4.83 \mathrm{~km} / \mathrm{h}$ & Standard & Standard \\
$(3 \mathrm{mile} / \mathrm{h})$ & & \\
\hline
\end{tabular}

not significantly difterent from each other. This is not to say that each bicycle is equally manoeuvrable on all tasks. The high-rise exhibited a slight performance edge on the tasks which required the greatest amount of manoeuvring. namely, the figure-eight cornering and slalom tasks. On the other hand, the results of the straight lane tracking at low speed suggest that the standard bicycle is more controllable. Rice and Rowland (1970) determined that the conventional bicycle was more controllable than the high-rise at speeds lower by 3 to $8 \mathrm{~km} / \mathrm{h}(5 \mathrm{mile} / \mathrm{h})$.

The adult subjects used in the study were mostly familiar with bicycles having the standard or race type of handlebars. 
Table 4: Mean ratings of task difficulty

\begin{tabular}{lcl}
\hline \multicolumn{1}{c}{ Manoeuvre } & Mean rating \\
\hline Tracking at $19.31 \mathrm{~km} / \mathrm{h}$ & 1.9 & $1=$ Very easy \\
$(12 \mathrm{mile} / \mathrm{h})$ & $2 \cdot 4$ & $2=$ Easy \\
Circle & $2 \cdot 6$ & \\
Lane change & $2 \cdot 7$ & $3=$ Neutral \\
Cornering & $2 \cdot 8$ & \\
Slalom & 3.0 & $4=$ Hard \\
Figure-eight & $3 \cdot 1$ & $5=$ Very hard \\
Tracking at $4.83 \mathrm{~km} / \mathrm{h}$ & & \\
$(3$ mile $/ \mathrm{h})$ &
\end{tabular}

While it was found that familiarity on these two types of bicycles had little effect on the relative performance attained with the bicycles, it is not known if the lack of prior experience with the high-rise handlebars reduced performance of the subjects riding that configuration. The results can at least be taken to show that the high-rise handlebars did not detract from performances compared with the standard handlebars.

The trend of the subjective ratings was similar to those of the measures of riding performance. On the average, subjects preferred the high-rise on the tasks involving skilled manoeuvring. However, the standard bicycle was considered easier to handle on those tasks where the greater stability was more likely to lead to better performance, namely the circle and lane change tasks, and straight lane tracking at low speed.

The race bicycle appeared to be the least manoeuvrable of the three. The analysis of subjects' performance, grouped by familiarity, suggests that subjects who were familiar with the race bicycle were somewhat more skilful. In order to be handled as easily as the others, the race bicycle probably required a higher level of proficiency.

The role of bicycle manoeuvrability in accidents is not known, but it would seem reasonable that a manoeuvrable and stable bicycle has characteristics that are needed for safe riding on streets in the mix of other traffic. The results of this study show that there is no reason to prohibit the high-rise handlebars, as was suggested by the US Food and Drug Administration.

The most recent proposal of the Consumer Product Safety Commission (1974) is that handlebar ends shall not be more than $406 \mathrm{~mm}$ ( $16 \mathrm{in}$ ) above the seat surface when it is in its lowest position, thus allowing the high-rise type of handlebars to be used.

On the other hand, the race bicycle offered the least manoeuvrability which was recently confirmed in another study (Purswell, Terrell and Greene, 1974). Since it is estimated that $40 \%$ of bicycles sold in the US were of this type in 1973, it is possible that for many, particularly inexperienced, cyclists this type is not the safest for their purposes.

\section{References}

Campbell, B.J., Foley, J.P., and Pascarella, E.A.

1971 Bicycle Riding and Accidents Among Youths: A Summary Report. The University of North Carolina Highway Safety Research Center, Chapel Hill, NC.

Consumer Product Safety Commission

1974 Bicycles: Establishment of Safety Standards and Proposed Labeling Requirements. Consumer Product Safety Commission Federal Register, 16 July, 39, No $137,26101-26113$.

\section{National Safety Council}

1970 Accident Facts.

1974 National Safety Council, Chicago.

\section{National Transportation Safety Board}

1972 Bicycle Use as a Highway Safety Problem. Bureau of Surface Transportation Safety, Report No NTSB-HSS72-1 Washington, DC.

\section{Ontario Department of Transport}

1970 An Investigation of Rider, Bicycle and Environmental Variables in Urban Bicycle Collisions. Ontario Department of Transport, Toronto Technical Bulletin No 70-1, October.

Purswell, J.L, Terrell, R. and Greene, J.

1974 A Study of Bicycle Design as it Affects Safety of Operation. Proceedings, 18th Annual Meeting of the Human Factors Society, Huntsville, Alabama, October.

Rice, R.S., and Roland, R.D.

1970 An Evaluation of the Performance and Handling Qualities of Bicycles. Cornell Aeronautical Laboratory, Inc. Buffalo, NY, Report CAL No VJ-2888-K.

US Department of Health, Education and Welfare

1972 Staff Analysis of Bicycle Accidents and Injuries. Bureau of Product Safety, Bethesda, Maryland. Report No PB-207-665. 